\title{
Ultraviolet (UV) transparent plastic claddings warm crops and improve water use efficiency
}

\author{
T.B. Williams ${ }^{1}$, N.D. Paul ${ }^{1}$, I. C. Dodd ${ }^{1}$, J.P. Moore ${ }^{2}$ and W, Sobeih ${ }^{2}$ \\ ${ }^{1}$ Lancaster Environment Centre, Lancaster University, Lancaster, LA1 4YQ; ${ }^{2}$ Arid Agritec, \\ Enterprise \& Business Partnerships, Lancaster University, Lancaster, LA1 4YQ
}

\begin{abstract}
Advances in the manufacturing of plastic cladding for protected crop cultivation have resulted in wavelength selective plastics capable of manipulating the transmission of solar radiation to include ultraviolet (UV: $280-400 \mathrm{~nm}$ ). Commercial growers already utilising these plastics report early maturity associated with warmer crops. We hypothesised that UV-B radiation causes partial stomatal closure that reduces stomatal conductance and transpiration rate, thereby increasing leaf temperature (relative to air temperature). We tested this hypothesis by investigating leaf gas exchange and temperature responses of individual tomato leaves to UV-B and UV-A radiation provided by UV lamps in a controlled environment. Transient $(90$ minutes) exposure to UV-B radiation decreased stomatal conductance but had minimal impact on photosynthesis, thus increasing leaf temperature and instantaneous water use efficiency. Should this enhanced water use efficiency also occur at a whole plant / canopy scale, these responses may benefit growers of protected crops in arid climates where plastic clad polytunnels are often utilised.
\end{abstract}

Keywords: protected crops, polytunnel, tomato, leaf temperature, instantaneous water use efficiency (WUEi)

\section{INTRODUCTION}

Technological advances in the manufacturing of plastic cladding for protected crop cultivation have resulted in wavelength selective plastics capable of manipulating the transmission of solar radiation to include ultraviolet (UV: 280-400 nm). UV transparent (UV-T) cladding that transmits the full range of solar UV (Paul et al., 2005; Paul et al., 2012) is already in use by commercial growers operating predominantly around the Mediterranean. Although the biology of crop responses to UV radiation has been well studied (e.g. Paul et al., 2005; Paul et al., 2012), understanding of the effects of UV-T plastics on the performance of commercial crops is still emerging. For example, we received repeated anecdotal reports from commercial growers that crops, including tomato, cultivated under UV-T cladding mature earlier than crops grown under "conventional" plastics that are opaque to all or part of solar UV radiation. Growers have associated this earlier maturity with increased leaf temperature under UV-T films. We are unaware of any published reports that exposure to solar UV radiation increases leaf temperature, but data collected on a commercial tomato farm in Antalya, Turkey confirmed that leaf temperature in a tomato crop grown under UV-T cladding was $1.9^{\circ} \mathrm{C}$ higher $(\mathrm{p}<0.05)$ than under standard diffuse plastic claddings (Table 1 ).

Table 1. Summary of leaf temperature data provided by commercial growers from a tomato farm in Antalya, Turkey. Data compares leaf temperature under diffuse UV transparent (UV-T) plastic cladding with diffuse standard plastic cladding which is opaque to part of solar UV radiation ( $\mathrm{t}=2.14, \mathrm{n}=40, \mathrm{p}<0.05)$.

\begin{tabular}{|l|cc|}
\hline Cladding Type & Leaf Temperature $\left({ }^{\circ} \mathrm{C}\right)$ & $\begin{array}{c}\text { Standard Error } \\
\left({ }^{\circ} \mathbf{C}\right)\end{array}$ \\
\hline UV-T (diffuse) & 33.5 & 0.64 \\
\hline
\end{tabular}




\begin{tabular}{|l|cc}
\hline Standard (diffuse) & 31.6 & 0.63 \\
\hline
\end{tabular}

While increased leaf temperature in response to solar UV radiation appears not to have been reported before, there is a substantial literature confirming that solar UV, especially UV-B radiation (280-315 nm) induces partial stomatal closure and so decreases stomatal conductance. This includes studies where UV radiation was provided using lamps (e.g. Nogues et al., 1998, 1999, He et al., 2005; Tossi et al., 2014) and where solar UV-B was attenuated using wavelength-selective filters (e.g. Kataria et al. 2013). These studies with differing methodological approaches demonstrate that UV-B decreases stomatal conductance independent of the experimental environment. As transpiration through stomata is one of the main leaf heat dissipation mechanisms, any closure would limit transpiration resulting in warmer leaves (Taiz and Zeiger, 2006).

In this study, we hypothesised that UV-B radiation would cause partial stomatal closure reducing transpiration rate, and thereby increasing leaf temperature (relative to air temperature). We tested this hypothesis by investigating leaf gas exchange and temperature responses of individual tomato leaves to UV-B and UV-A radiation provided by UV lamps, in a controlled environment over 90 minutes. In addition, any effect on instantaneous water use efficiency, the ratio of carbon assimilation to transpiration, was analysed.

\section{MATERIALS AND METHODS}

\section{Plant material and cultivation}

Tomato (Solanum lycopersicum cv. 'Money Maker') plants were propagated in the absence of UV-B radiation in a glasshouse at the Lancaster Environment Centre. Seeds were sown in tray inserts containing a peat-based substrate (Levington Advance M3, ICL Everris Ltd, Ipswich) and were $\sim 2$ weeks old (depending on the season) when they were transplanted individually into $2 \mathrm{~L}$ pots containing the same substrate. After $\sim 4$ weeks of growth from seed, the most uniform individually potted tomato plants were selected and transferred to the controlled environment to acclimate to the different conditions to those present in the glasshouse, for $\sim 1$ week prior to use in experimentation. At $\sim 5$ weeks old, the eight most uniform plants were selected for experimentation. A leaflet from the most recent fully developed leaf pair on the $5^{\text {th }}$ internode was used for the experiment.

\section{Controlled environment (CE) conditions and radiation sources}

The experiments were conducted in a climate cabinet (Microclima 1750, Snijder Scientific, Tilburg, Holland). This provided relatively stable temperature and humidity control, vital for measurements of stomatal behaviour and leaf temperature, and constant PAR for each experiment repetition. A second climate cabinet was used for acclimation of plants transferred from the glasshouse. Each cabinet provided $\sim 300 \mathrm{umol} \mathrm{m}^{-2} \mathrm{~s}^{-1}$ PAR without UV radiation (excluded by Lightworks sun master plastic film (Arid Agritec, Lancaster, UK) that filtered out UV radiation $<400 \mathrm{~nm}$ ) for a 16 -h photoperiod. The temperature was $25^{\circ} \mathrm{C}$, relative humidity was $60 \%$ and $\mathrm{CO}_{2}$ was $400 \mathrm{ppm}$. Both Snijder climate cabinets had identical environmental settings to avoid any "transfer shock" when plants were moved between cabinets.

UV radiation was provided by a different source to PAR. Fluorescent tubes (FTs) were used to provide UV-A (Q-Lab UVA-340) or UV-B (Q-Lab UVB-313 EL, both Q-Panel Lab Products, Cleveland, USA) radiation in separate experiments. UV radiation was quantified with a spectroradiometer (model SR9910-V7, Macam Photometrics, Livingston, UK) that provided the spectral irradiance $(280-800 \mathrm{~nm}$ ) of each source (Tab. 2). UV treatments were expressed as (i) total unweighted irradiance, (ii) irradiances weighted using the plant growth inhibition action spectrum (PGIAS; Flint and Caldwell, 2003) and the (iii) irradiances weighted using the generalised plant action spectrum (GPAS; Caldwell, 1971). We used PGIAS in our experimental design because its inclusion of UV-A suggests it is the more 
appropriate weighting function. However, since GPAS has been used in the majority of UV studies that have utilised a biological spectral weighting function (BSWF), we have quoted this to allow direct comparison with previous studies (Tab. 2). These action spectra, or BSWFs, are vital for comparison of scientific studies because UV radiation sources, whether artificial or solar, emit radiation of variable quantities at different wavelengths. To understand the relative effect of these variations the irradiance at each wavelength is weighted based on a specific biological effect (e.g. growth inhibition in PGIAS). These action spectra allow comparisons between solar UV and UV from lamps, which have very different spectral distributions. UV-A irradiances (unweighted) were matched with the unweighted UV-B irradiances (applicable to the selected weighted irradiances) to ensure an equal total radiation loading independent of the UV wavelengths applied. UV irradiance was varied by changing the distance between the experimental leaf and the UV radiation source, ensuring that leaves remained equidistant from the PAR source, by raising or lowering the lamp on a clamp.

Table 2. Unweighted and weighted irradiances at 240-800 nm. Unweighted irradiances include the Snijder climate cabinet photosynthetically active radiation source in addition to the associated UV lamp irradiance. The weighted irradiances refer to the UV irradiance alone, weighted by the Generalised plant action spectrum (GPAS: Caldwell, 1971) and the Plant growth inhibition action spectrum (PGIAS: Flint and Caldwell, 2003).

\begin{tabular}{|c|c|c|c|}
\hline Treatment & $\begin{array}{l}\text { Unweighted } \\
\text { Irradiance } \\
280-800 \mathrm{~nm} \\
\left(\mathrm{~W} \mathrm{~m}^{-2}\right)\end{array}$ & $\begin{array}{c}\text { GPAS Weighted } \\
\text { Irradiance } 280-800 \\
\text { nm }\left(W \mathbf{~ m}^{-2}\right)\end{array}$ & $\begin{array}{l}\text { PGIAS Weighted } \\
\text { Irradiance } 280-800 \\
\text { nm }\left(W ~ m^{-2}\right)\end{array}$ \\
\hline Control & 45.04 & 0.000 & 0.000 \\
\hline UV-B FT 0.100 & 44.13 & 0.100 & 0.097 \\
\hline UV-B FT 0.260 & 43.25 & 0.260 & 0.251 \\
\hline UV-A FT $0.260 \mathrm{e}$ & 42.87 & 0.029 & 0.111 \\
\hline UV-B FT 1.08 & 50.75 & 1.080 & 1.120 \\
\hline UV-B FT 2.55 & 56.68 & 2.550 & 2.640 \\
\hline
\end{tabular}

\section{Leaf gas exchange and temperature measurements}

Leaf gas exchange and temperature measurements were made using a LI-COR 6400 (LI-COR Inc., Lincoln, NE, USA). The LI-COR 6400 'clear window' ('Teflon") cuvette attachment allowed transmission of PAR and UV radiation to the experimental leaf enclosed inside. Once a leaf was enclosed inside the cuvette, the internal environment was allowed to stabilise for 15 minutes before the application of UV for 90 minutes. The LI-COR 6400 also provided an additional level of environmental control, which dampened the cyclic fluctuations in CE temperature that are inherent to climate cabinet temperature control.

\section{Effects of leaf excision on leaf temperature}

In separate experiments, gas exchange and leaf temperature measurements were also performed on leaves that were excised from the plant after 15 minutes of stabilisation in the LI-COR 6400 cuvette. Excision causes rapid and complete stomatal closure and so provides a measure of the maximum possible effect of stomatal closure on leaf temperature under our experimental conditions.

\section{Data processing}

Air temperature fluctuations profoundly influence leaf temperature, especially if stomata are not transpiring fully due to partial closure, reducing the plant's ability to 
regulate leaf temperature. To account for this, the difference between leaf and air temperature $\left(\mathrm{T}_{\text {leaf }}-\mathrm{T}_{\text {air }}\right)$ is determined for each data point. The change in this difference was then measured over the 90 minute treatment period. The effect of UV radiation on this difference between leaf and air temperature over this time period is referred to here as $\Delta T$ ( $T_{\text {leaf }}-T_{\text {air }}$ ) (Fig. 1), and was calculated as follows:

$\Delta \mathrm{T}\left(\mathrm{T}_{\text {leaf }}-\mathrm{T}_{\text {air }}\right)=\left(\mathrm{T}_{\text {leaf }}-\mathrm{T}_{\text {air }}\right)_{\text {AFTER }}-\left(\mathrm{T}_{\text {leaf }}-\mathrm{T}_{\text {air }}\right)_{\text {BEFORE }}$
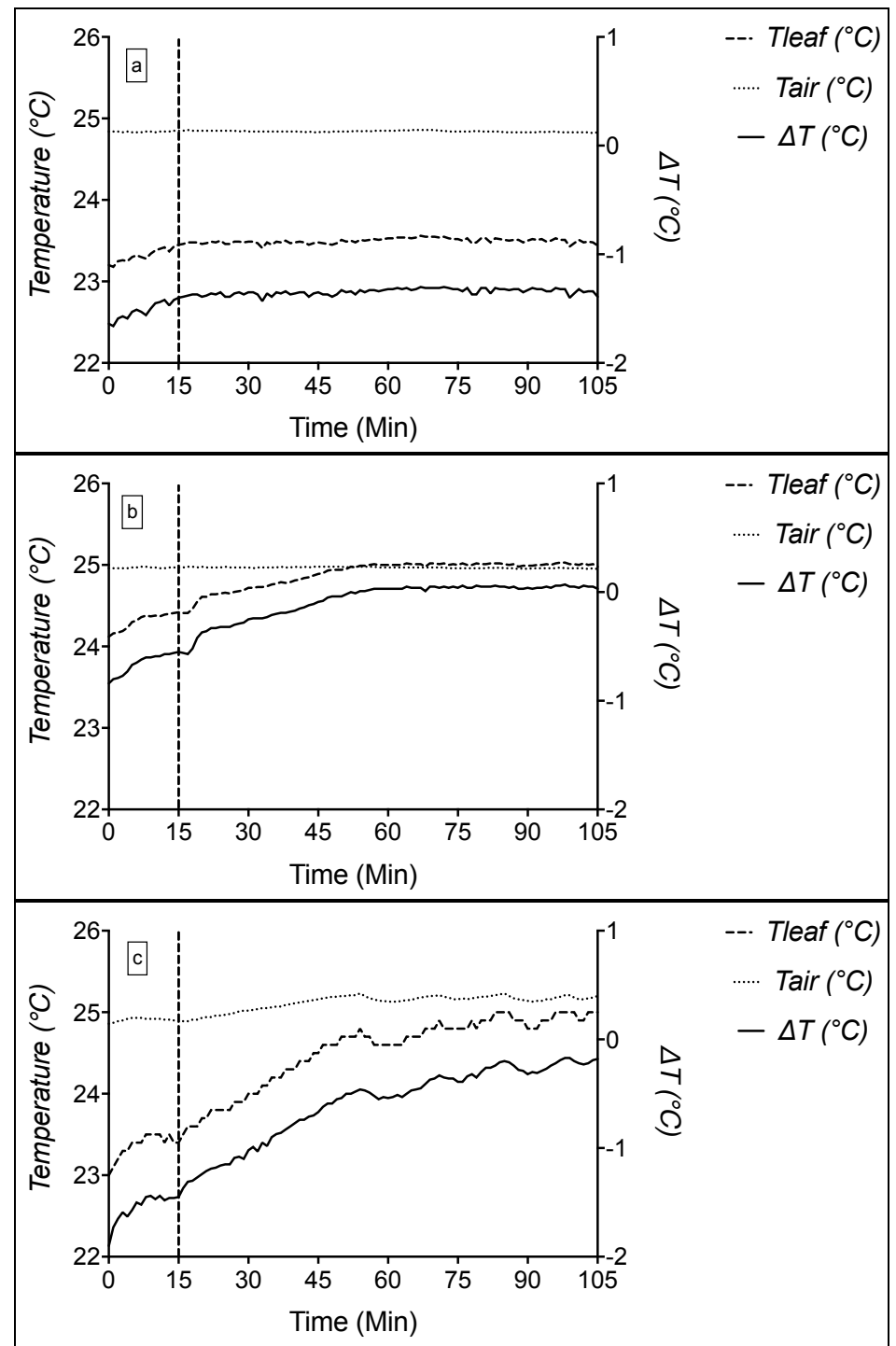

Figure 1. Example time courses of $T_{\text {leaf }}, T_{\text {air }}$ and the resulting $\Delta T$ ( $T_{\text {leaf }}-T_{\text {air }}$ ) for (a) Control, (b) leaf excision and (c) UV-B treatments. At zero minutes the leaf was enclosed in the LI-COR 6400 cuvette and data logging started. The conditions inside the cuvette were allowed to stabilise for 15 minutes without further treatment. After 15 minutes (vertical dashed line), the treatment was maintained (a), the leaf was excised (b) or UV-B was applied (c) for another 90 minutes. The UV treatments were weighted by the Plant growth inhibition action spectrum (PGIAS: Flint and Caldwell, 2003). 


\section{Statistical analysis}

For each treatment 8 replicates were statistically analysed using a one-way repeated measures analysis of covariance (ANCOVA) with the pre-UV treatment values as the covariate and Bonferroni post hoc comparisons using SPSS version 24 (SPSS Inc. Chicago, USA). Regression analysis determined relationships between leaf temperature, stomatal conductance and PGIAS weighted UV irradiance using GraphPad Prism version 7.0d for Mac OS X (GraphPad Software, La Jolla California USA, www.graphpad.com).

\section{RESULTS AND DISCUSSION}

\section{The time course of stomatal responses}

Example time courses of the three treatments (control, leaf excision, UV-B irradiation) demonstrate typical leaf temperature responses and how $\Delta T\left(T_{\text {leaf }}-T_{\text {air }}\right)$ was derived from measurements of Tleaf and Tair (Figure 1). For each experiment, a leaf was enclosed in the LI-COR 6400 cuvette then data was logged. Conditions inside the cuvette were allowed to stabilise for 15 minutes, then the treatment was maintained (Fig.1a), the leaf was excised (Fig.1b) or UV-B was applied (Fig.1c). In each case Tair remained relatively stable $\left( \pm 0.2^{\circ} \mathrm{C}\right)$ throughout. Control leaves also exhibited relatively stable Tleaf resulting in a stable $\Delta T\left(T_{\text {leaf }}{ }^{-}\right.$ $\left.T_{\text {air }}\right)$. Excised leaves exhibited a sharp increase in Tleaf and $\Delta T\left(T_{\text {leaf }} T_{\text {air }}\right)$ a few minutes after excision, which gradually plateaued. UV-B treated leaves exhibited an immediate but more gradual increase in Tleaf and $\Delta T\left(T_{\text {leaf }} T_{\text {air }}\right)$.

\section{$\mathrm{UV}$ radiation reduces stomatal conductance and increases leaf temperature}

Increased UV-B irradiances (PGIAS weighted) significantly reduced stomatal conductance (Fig. 2a), and significantly increased $\Delta T$ ( $T_{\text {leaf }} T_{\text {air }}$ ) (Fig. 2b). UV-B radiation increased $\Delta T$ ( $\left.T_{\text {leaf }}-T_{\text {air }}\right)$ by up to $0.88^{\circ} \mathrm{C}$ (Fig.2b), compared to a maximal temperature increase (i.e. that caused by leaf excision) of $1.14^{\circ} \mathrm{C}$ (Fig. 1b). Further analysis suggests that two elements contributed to leaf warming: direct radiative heating from the UV lamp and partial stomatal closure. For a given reduction in transpiration rate over the course of measurement, the concurrent increase in $\Delta T\left(T_{\text {leaf }}-T_{\text {air }}\right)$ was up to $0.48^{\circ} \mathrm{C}$ greater in response to UV treatments than in controls and in response to leaf excision. We attribute this increase to direct radiative heating from the UV source, which is clearly not present in the 'control' and 'leaf excision' treatments that provided no additional heat input. When this temperature increase caused by radiative heating from the UV lamp is deducted from the overall leaf warming results the leaf warming resulting from partial stomatal closure in response to UV radiation was up to $0.4^{\circ} \mathrm{C}$. This was in response to the maximum PGIAS weighted UV irradiance used here $\left(2.64 \mathrm{~W} \mathrm{~m}^{-2}\right)$ which is approximately double the global maximum PGIAS weighted irradiance occurring the field.

In the specific radiative loading environment of the Snijder climate cabinet, leaf excision experiments demonstrated that the maximum degree of relative leaf warming $(\Delta T$ $\left(T_{\text {leaf }} T_{\text {air }}\right)$ ) that could occur was $1.14^{\circ} \mathrm{C}$. Thus the maximum relative leaf warming $\left(0.4^{\circ} \mathrm{C}\right)$ attributable to UV-B radiation was $35 \%$ of the maximum possible in that environment. However, these controlled environment conditions are substantially different from the field, notably in terms of a much lower total radiative loading than is present in sunlight. As a result, partial stomatal closure caused by UV-B exposure under UV-T cladding in polytunnels would be expected to have a greater effect on leaf temperature than we recorded in our controlled environments, consistent with reports from commercial growers of far greater leaf temperature increases of up to $2^{\circ} \mathrm{C}$ (Tab. 1). 


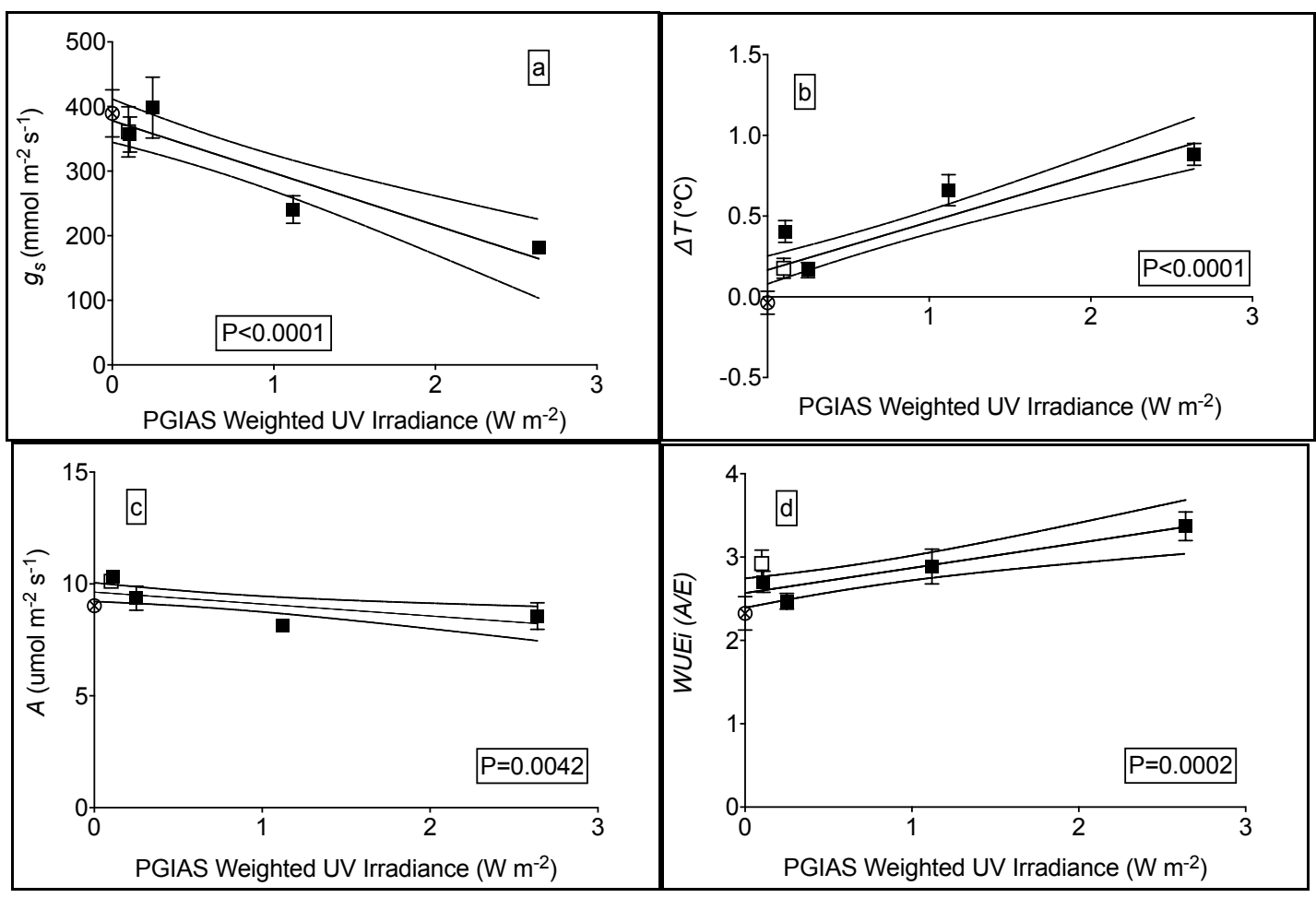

Figure 2. The dose response of (a) stomatal conductance $\left(g_{s}\right)$, (b) relative leaf temperature $\left(\Delta T\left(T_{\text {leaf }}-T_{\text {air }}\right)\right)$, (c) $\mathrm{CO}_{2}$ assimilation rate $(A)$ and (d) instantaneous water use efficiency (WUEi: the ratio of assimilation rate $(A)$ to transpiration rate $(E)$ ) to different UV treatments over 90 minutes (solid and open symbols represent UV-B and UV-A respectively, hatched circle was control). The UV treatments were weighted by the Plant growth inhibition action spectrum (PGIAS: Flint \& Caldwell, 2003). Regression analysis (P Values indicated) confirmed a linear model fitted best for each parameter. Dotted lines represent the $95 \%$ confidence interval of the linear regression. Error bars represent $\pm 1 \mathrm{SE}(\mathrm{n}=8)$.

\section{UV radiation enhances water use efficiency}

Instantaneous water use efficiency (WUEi) was significantly increased as a result of the reduction in stomatal conductance in the absence of any significant changes in photosynthesis (Fig. 2c, d). Whether this increase in WUEi is sustained over a longer period of UV exposure (than 90 minutes) requires additional experiments. However, the consensus in the literature is that variation in UV radiation within the ambient range rarely causes significant inhibition of photosynthesis (Aphalo et al., 2015; Kataria et al., 2014; Singh et al., 2014).

\section{CONCLUSIONS}

UV radiation significantly decreased stomatal conductance thereby increasing $\Delta T$ ( $\left.T_{\text {leaf }}-T_{\text {air }}\right)$. Since our treatments were very short, (90 minutes) the measured responses cannot have been due to longer-term responses to UV radiation, such as changes in stomatal distribution or cuticle properties (e.g. Nogues et al., 1998, 1999; Gonzalez et al., 1996) that might affect transpiration, and hence leaf temperature, under commercial conditions. However, our data do corroborate the reports from commercial growers of higher leaf temperature and warmer crops when cultivated under UV-T plastic claddings in protected cultivation. While those reports confirm that this warming is commercially beneficial for 
some crops at some times of year, we recognise that under other conditions warming might lead to additional heat stress. Further investigation is required to assess the agronomic value of leaf warming under UV-T cladding, alongside the wider benefits of cultivation under such films (Paul et al., 2005; Paul et al., 2012). To our knowledge, previous reports have not included increased instantaneous water use efficiency as an agronomic benefit of exposure to UV-B radiation. However, this response may assist growers of protected crops in arid climates to minimise their water use.

\section{ACKNOWLEDGEMENTS}

The authors want to thank the Biotechnology and Biological Sciences Research Council (BBSRC) and Arid Agritec for their funding of the research for this paper.

\section{Literature cited}

Aphalo, P. J., Jansen, M. A. K., Mcleod, A. R., and Urban, O. (2015). Ultraviolet radiation research: from the field to the laboratory and back. Plant, Cell and Environment, 38, 853-855 doi: 10.1111/pce.12537.

Caldwell, M. M. (1971). Solar UV irradiation and the growth and development of higher plants. In: Photophysiology. Ed. by A. C. Giese. Vol. 6. (New York: Academic Press), p.131-177.

Flint, S. D., and Caldwell, M.M. (2003). A biological spectral weighting function for ozone depletion research with higher plants. Physiologia Plantarum. 117, 137-144.

Gonzalez, R., Paul, N. D., Percy, K., Ambrose, M., McLaughlin, C. K., Barnes,J. D., Areses, M., and Wellburn, A.R. (1996). Responses to ultraviolet-B radiation (280-315 $\mathrm{nm}$ ) of pea (Pisum sativum) lines differing in leaf surface wax. Physiologia Plantarum. 98, 852-860.

He, J.-M., Xu, H., She, X.-P. Song, X.-G. and Zhao, W.-M. (2005). The role and Interrelationship of Hydrogen Peroxide and Nitric Oxide in the UV-B-Induced Stomatal Closure in Arabidopsis Leaves. Functional Plant Biology, $32,237-247$.

Jansen, M. A. K and Noort, R. E. (2000). Ultraviolet-B radiation induces complex alterations in stomatal behaviour. Physiologia Planatarum, 110, 189-194.

Kataria, S., Guruprasad, K. N., Ahuja, S. and Singh, B. (2013). Enhancement of growth, photosynthetic performance and yield by exclusion of ambient UV components in C3 and C4 plants. Journal of Photochemistry and Photobiology B: Biology, 127, 140-152 doi: 10.1016/j.jphotobiol.2013.08.013.

Kataria, S., Anjana, J. and Guruprasad, K. N. (2014). Impact of increasing Ultraviolet-B (UV-B) radiation on photosynthetic processes. Journal of Photochemistry and Photobiology B, 137, 55-66 doi: 10.1016/j.jphotobiol.2014.02.004.

Madronich, S. (1993). UV radiation in the natural and perturbed atmosphere, in Environmental Effects of UV (Ultraviolet) Radiation. M. Tevini, ed., (Lewis Publisher, Boca Raton), p.17-69.

Nogues, S., Allen, D. J., Morison, J. I. L. and Baker, N. R. (1998). Ultraviolet-B Radiation Effects on Water Relations, Leaf Development, and Photosynthesis in Droughted Pea Plants. Plant Physiology, 117, 173-181.

Nogues, S., Allen, D. J., Morison, J. I. L. and Baker, N. R. (1999). Characterization of Stomatal Closure Caused by Ultraviolet-B Radiation. Plant Physiology, 121, 489-496.

Paul, N. D., Jacobsen R. J., Taylor, A., Wargent J. J., and Moore, J. P. (2005). The use of wavelength-selective plastic cladding materials in horticulture: Understanding of crop and fungal responses through the assessment of biological spectral weighting functions. Photochemistry and Photobiology, 81, 1052-1060.

Paul, N. D., Moore, J. P., McPherson, M., Lambourne C., Croft, P., Heaton J. C. and Wargent J. J. (2012). Ecological responses to UV radiation: interactions between the biological effects of UV on plants and on associated organisms. Physiologia Plantarum, 145, 565-581.

Singh, S., Agrawal, S. B. and Agrawal, M. (2014). UVR8 mediated plant protective responses under low UV-B 
radiation leading to photosynthetic acclimation. Journal of Photochemistry and Photobiology B, 137, 67-76.

Taiz, L. and Zeiger, E. (2006). Plant Physiology. Sunderland: Sinauer Associates.

Tossi, V., Lamattina, L., Jenkins, G. I. and Casia, R. O. (2014). Ultraviolet-B-Induced Stomatal Closure in Arabidopsis Is Regulated by the UV RESISTANCE LOCUS8 Photoreceptor in a Nitric Oxide-Dependent Mechanism. Plant Physiology, 164, 2220-2230. 